\title{
If it can be done, it should be done,...or not?
}

\author{
André Grotenhuis ${ }^{1}$
}

Received: 1 February 2016 / Accepted: 2 February 2016/Published online: 13 February 2016

(C) Springer-Verlag Wien 2016

In this issue, Feletti and colleagues have published an interesting case report: "Transaqueductal trans-Magendie fenestration of arachnoid cyst in the posterior fossa" [2]. The case they present is that of a 65 -year-old female with a retrocerebellar (cisterna magna) arachnoid cyst, clearly growing over an 8year period, with increasing symptoms of ataxia, asthenia and headache. The authors stated that there was an obstructive triventricular hydrocephalus. The authors describe a triventricular hydrocephalus also with an enlarged aqueduct. On their figure 1a and $b$, there is indeed an increase in the size of the cyst, but the aqueduct is patent and, to my understanding, not widened. Therefore, it was difficult to imagine a triventricular hydrocephalus with a patent aqueduct and normal-sized fourth ventricle caused by a retrocerebellar cyst, apparently closing of the foramen of Magendie. If this had also obstructed the foramina of Luschka, I would have expected a quadriventricular hydrocephalus, thus also involving the fourth ventricle. I wondered if the patient's symptoms such as ataxia could also "just" have been caused by the enlarging cyst itself. The authors state that their primary aim was to perform an ETV to resolve the problem of hydrocephalus, and their secondary aim was to determine whether the cyst could be reached, but then, in the description of the surgical procedure, it was apparent that the cyst itself was their first target. At the end of the detailed description of the cyst fenestration, they write "An ETV was also performed, as initially planned". If the ETV was their primary aim, that should have been performed as a first step.

\section{André Grotenhuis}

Andre.Grotenhuis@radboudumc.nl

1 Department of Neurosurgery, Radboudumc, Geert Grooteplein Zuid 10, 6525 GA Nijmegen, The Netherlands
Ultimately, they managed the cystic lesion adequately, with good results and no complications. But I was puzzled why they chose this very long and curved trajectory with a much higher risk of possible complications compared to fenestrating this cyst from a small suboccipital approach, which could have been done without passing through the brain at all. The authors are right that in case of a quadrigeminal cyst with compression of the aqueduct, the aqueductal obstruction/ stenosis does not always open up after cyst fenestration. But in their case the aqueduct was open and of normal size, as was the fourth ventricle, so one would expect to reopen the CSF passageway fenestrating this retrocerebellar cyst via the more established suboccipital approach.

Considering the route, from a precoronal burr hole they entered the frontal horn with a peel-away sheath. The precoronal burr hole usually gives a straight-line access to the anterior part of the third ventricle, e.g., for an ETV. So with the flexible endoscope, they passed the foramen of Monro. But when navigating through the aqueduct (I assume the flexible endoscope had a 4-mm diameter; the aqueduct, however, considering the provided image, was of similar size at best), how could they control what the shaft of the endoscope was doing to the edge of the foramen of Monro (i.e., the fornix)? Proceeding through the aqueduct and fourth ventricle to fenestrate the cyst at the foramen of Magendie, what happened with the shaft of the flexible endoscope (the final $2 \mathrm{~cm}$ of which can be steered) that is now in an S-shaped trajectory through the frontal horn-foramen of Monro-interthalamic adhesion-aqueduct?

Transaqueductal endoscopy from a frontal horn approach has been described previously (I described it myself in my endoscopic guidebook in 1995), but then mostly as a "mother-baby principle", in which the posterior part of the third ventricle is reached with a rod lenscope and then a smaller flexible endoscope is passed through the working channel of 
that scope into the aqueduct to reach a target in the upper part of the fourth ventricle. In this way, the lenscope can always control the position of the shaft of the flexible endoscope. Furthermore, the image quality of a flexible endoscope is well below that of a rod lenscope. The size of the working channel is also much smaller, usually only $1.5 \mathrm{~mm}$, so the instruments are also smaller. The authors have provided very nice and clear images, yet they did not mention anything about the specifics of the flexible endoscope that was used or about the size of the fenestration they were able to create. But since the cyst collapsed and has not recurred over the past 2 years, it was apparently sufficient.

Finally, the authors made a remark that included a warning: Such a procedure as described here should only be performed by neurosurgeons who are very experienced in neuroendoscopy. Contemplating this warning and considering myself rather experienced in neuroendoscopy, my first thought was: if you are experienced, you would not choose such an approach in the first place.

But how do we gain experience? I was thinking back to my very first endoscopic case in 1989, an infant with hydrocephalus and a unilaterally hugely enlarged choroid plexus. I decided to borrow an endoscope from paediatric urology, made an occipital burr hole and looked into the ventricle to see whether this was a plexus papilloma or "just" an enlarged normal choroid plexus and took a biopsy. I had never done this before (only several times in the anatomy laboratory), and still I thought doing this before eventually going on with a craniotomy to remove the papilloma was in the best interest of this little girl. A second case followed in which a young adult male had been diagnosed as a young boy with a pineal lesion with hydrocephalus in the 1970s. He had been shunted and irradiated (without any histological confirmation at that time). It went well, except for an early shunt revision, and then he came in with a shunt dysfunction more than 17 years later when he was 22 years old. One and a half years and 36 more shunt revisions later, he could not bear it anymore, and we were also desperate and out of options to make the shunt work again.

I then proposed performing an endoscopic third ventriculostomy and told the patient honestly that I had never done this on a patient before but numerous times in the laboratory. He agreed within the blink of an eye (he probably would have consented to being shot to the moon and back, too). So I proceeded, and the situation was very much like in the laboratory (which means rather small ventricles and no translucent floor!). I performed the ETV, removed his whole shunt, and did not leave an EVD or reservoir as an escape because it did not even enter my mind that failure was possible. The patient was fine after surgery, and I told him that we now had cured his hydrocephalus. It all went well, and since then he has never had another surgery for hydrocephalus (so it came close to a cure!), but many years and many procedures later, I have often thought of this case and said to myself: if you act stupidly, you better be lucky.
In medicine, and certainly in the surgical disciplines, there is a constant drive to push the borders of our present technology ahead, to do what never has been done before. We consider this as progress. Numerous examples pave the path of medical history. Where would we be now without those pioneers who dared to transplant a human kidney or human heart into the body of another human being or in our own field without somebody to introduce a microscope into the operating room, to put a fiberoptic cable into the brain of a trauma victim, to place a spring-type clip onto a ready-to-ruptureagain intracranial aneurysm, or to use a catheter all the way up such an aneurysm and place platinum coils in it?

What is common in all new developments in our specialty (and throughout medicine) is that it all passes through three stages. First, it is ridiculed. Second, it is violently opposed. Third, it is accepted as being self-evident. It is similar to what Mahatma Gandhi stated: "First they ignore you, then they laugh at you, then they fight you, then you win".

In endoscopic surgery, the progress in devices and techniques over the last 3 decades has been unprecedented. It seems almost beyond belief now that the early pioneers in the late 1980s were criticised so harshly for their early work in neuroendoscopy. I still remember my first presentation on the use of a small endoscope during aneurysm clipping. It was ridiculed by most and derided as unethical by others. And once, during a presentation on endoscopic biopsy of pineal tumours, suddenly the slide projector was unplugged with the explanation by the session chairman that such unethical neurosurgery should not be presented.

Ensuring the safety of new techniques and procedures indeed has its challenges. There are regulations worldwide for diagnostics, new drugs and medical devices - however, there is no such regulation for new surgical procedures [9]. Not all was done well regarding the implementation of neuroendoscopy. There have been marketing influences and overall a rather loosely structured implementation of different endoscopic procedures. These have been questioned, and lessons were learned. Notably, neurosurgeons are now more mindful of those lessons.

However, we have to realise that there is a grey zone between what can be done, what should be done and what has not been done before and in these situations consider whether ethics board permission is required. Ethical considerations relevant to the implementation of a new surgical technique or procedure could include the following: (1) How is the safety of a new technique or procedure ensured? (2) What are the timing and processes by which such a new technique or procedure should be implemented in clinical practice? (3) How are patients informed before undergoing a new procedure? (4) How are surgeons trained and credentialed in a new technique or procedure? (5) How are the outcomes of a new technique or procedure evaluated? (6) How are the responsibilities to individual patients and society at large balanced [11]? 
While the gold standard for clinical research remains the randomised clinical trial (RCT), this is still not the case for surgical research although there has been a call for a more methodologically rigorous evaluation of both novel and wellestablished surgical procedures and their outcomes [10]. A surgical RCT may compare two different surgical procedures or may compare surgery with nonsurgical management or with the natural history of the disease being studied. For a surgeon-researcher to enrol patients in an RCT, it is widely accepted that a state of "clinical equipoise" must exist [12].

Freedman coined the term clinical equipoise as a state where "there is no consensus within the expert clinical community about the comparative merits of the alternatives to be tested" with "honest, professional disagreement among...clinicians". If such a state exists, then a clinical trial is considered ethical provided it is designed to provide an answer as to which arm of the study is better. The key to Freedman's concept of clinical equipoise, as opposed to an individual clinician's uncertainty regarding the superiority of one intervention over another (also known as the "uncertainty principle"), is that it allows an individual clinician-researcher to have a preference or opinion as to which intervention they believe to be superior and still enrol patients in a clinical trial, provided they "recognize that their less-favoured treatment is preferred by colleagues whom they consider to be responsible and competent" [3].

But this is even more difficult when offering a new or at least less well-established procedure to one's patient outside a clinical trial. On what ethical grounds may a doctor offer this to the patient? The answer seems to depend greatly the side of the Atlantic on which you reside. In Europe, the uncertainty principle is widely endorsed. However, in North America, clinical equipoise - reflecting collective uncertainty - is the dominant ethical basis $[1,8,11]$. It is widely acknowledged that doctors have a primary duty to promote their patients' welfare. When doctors become investigators, however, other ends such as improving one's own surgical skills, gaining experience in treating a rare condition and being the first to have done it may conflict with this duty.

The uncertainty principle seems to offer an appealing solution to this problem. Doctors who are convinced, whether for a wise or silly reason, that one treatment is better than another for a particular patient cannot ethically choose at random which treatment to give; they must do what they think is best for the patient. On the other hand, if the doctor is uncertain about which treatment is best for a patient, offering the patient a choice between what he or she believes to be equally preferred treatments is acceptable and does not violate his or her duty. But this principle is not a solid moral basis for offering a choice between a well-established procedure with a known riskversus-benefit ratio and a new procedure with an unknown risk-benefit profile [12], because under the uncertainty principle it would be difficult, if not impossible, to conclude that a doctor ever errs in offering a patient a new procedure. So long as the doctor claims he or she was uncertain, even if madly or incompetently so, he or she cannot be said to be wrong. Recent articles on the uncertainty principle have added "reasonably" and "substantially" to qualify uncertainty. But who decides what counts as reasonable or substantial uncertainty? If it is the individual doctor - and the uncertainty principle maintains that the proper normative locus for decision making is the individual doctor-we are left with the same problem.

Clinical equipoise, on the other hand, recognises that it is not the individual doctor but the community of doctors that establishes standards of practice. According to Freedman, the ethics of medical practice grant no ethical or normative meaning to a treatment preference, however powerful, that is based on a hunch or anything less than evidence publicly presented and convincing to the scientific community. Medical students will be licensed as doctors after they demonstrate the acquisition of this professionally validated knowledge, not after they reveal a superior capacity for guessing.

Competent medical practice is defined widely as that which falls within the bounds of the standard of care - that is, a practice endorsed by at least a respectable minority of expert practitioners. The innovation of clinical equipoise is the recognition that a new surgical procedure (or a much less wellestablished procedure like in this case report) is potentially consistent with this standard of care. Thus, a neurosurgeon, consistent with his or her duty to the patient, may offer such a new procedure when there "exists....an honest, professional disagreement among expert clinicians about the preferred treatment". The lines between regular clinical practice, innovation and surgical research are often difficult to draw.

Our oath as medical doctors contains the phrase "primum non nocere", first do no harm. Although the origin of the phrase is uncertain, it is accepted throughout the medical community. The Hippocratic Oath includes the promise "to abstain from

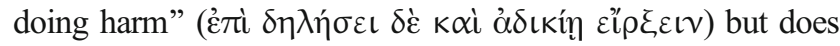
not include the precise phrase. Perhaps the closest approximation can be found in the Hippocratic Corpus in Epidemics: "The doctor must have two special objects in view with regard to disease, namely, to do good or to do no harm" (book I, sect.

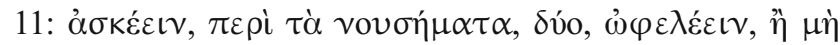
$\beta \lambda \alpha ́ \pi \tau \varepsilon \downarrow v)$ [5]. This is still the common practice in neurosurgery and in medicine in general. We consider the different options, to operate or not, and if we do operate, we then consider what procedure to use. The concept of non-maleficence, which is derived from this maxim, is one of the principal precepts of bioethics that all medical students are taught and is a fundamental principle throughout the medical world. Another way to state it is that, "given an existing problem, it may be better not to do something, or even to do nothing, than to risk causing more harm than good". It reminds us that we must consider the possible harm that any intervention might do. It is invoked when debating the use of an intervention that carries an obvious risk of harm but a less certain chance of benefit. 
Throughout the centuries this has been reflected in the claims that medicine, as an art, is the understanding or doctrine drawn from true, certain, universal and mutually consistent precepts directed to a single end, bringing together the four epistemological virtues of truth, certainty, objectivity and coherence, and linking them to the goal-directedness of art. Such claims for medicine are not easy to reconcile with either Galen's and Celsus's description of medicine as "ars coniecturalis", an art based upon conjecture, i.e. forming an idea without having much information to base it on, which is used contingently to determine the remedies appropriate to individual cases [6].

From ancient times on there has been a schism between caring for and helping the patient while that patient is simultaneously the object of our studies, our research. It has been pointed out that many different approaches to the truth need to be adopted in medicine because "man is an imperfect, changeable, variable, blind animal faced with an art of great length whose content is continually changing" [6].

This brings us back, again, to the cradle of our civilisation, ancient Greece. "Nothing endures but change" ( $\pi$ óv $\tau \alpha \chi \omega \rho \varepsilon \tilde{\varepsilon}$

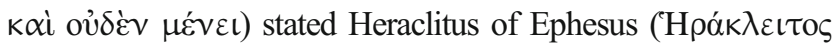
ca. $535 \mathrm{BC}-475 \mathrm{BC}$ ), a Greek philosopher known for his doctrine that change is central to the universe and for establishing the

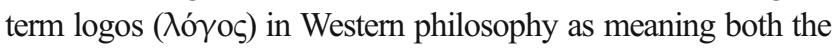
source and fundamental order of the cosmos. It is also reflected in his statement "You cannot step twice into the same river" ( $\delta i \varsigma$

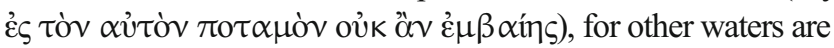
ever flowing past you. It is what we see in daily practice: there is never an identical second case, although they can seem to be similar, and yet we build our experience on it [4].

Among nineteenth century philosophers, Arthur Schopenhauer (22 February 1788-21 September 1860), a German philosopher, is most famous for his work Welt als Wille und Vorstellung (The World as Will and Representation) first published in 1819. He was among the first to contend that at its core the universe is not a rational place. And the ancient thought of Heraclitus is reflected in his statement: "Change alone is eternal, perpetual, immortal". Inspired by Plato and Kant, both of whom regarded the world as being more amenable to reason, Schopenhauer changed the reasoning and rationale in their works and developed their philosophies into an instinct-recognising and ultimately ascetic outlook, emphasising that in the face of a world filled with endless strife, we ought to minimise our natural desires for the sake of achieving a more tranquil frame of mind and a disposition towards universal beneficence. "Der Mensch kann tun was er will; er kann aber nicht wollen was er will". Man can do what he wills but he cannot will what he wills. Often considered to be a thoroughgoing pessimist, Schopenhauer, in fact, advocated ways - via artistic, moral and ascetic forms of awareness - to overcome a frustration-filled and fundamentally painful human condition. His philosophy holds a special attraction for those who wonder about life's meaning, along with those engaged in music, literature and the visual arts [13].
Finally, we have to realise that the role of the patient in the clinical application of new devices, techniques and procedures is paramount, and their welfare and interests must be protected. Patients present to surgeons with a wide variety of educational and cultural backgrounds, and at times they present with limited, scientifically imperfect information received from enthusiastic proponents in the industry, media and Internet. The resulting informed consent discussion may be even further challenged by a limited collective experience with the new technology/approach, including a limited ability to predict long-term results. While discussing the potential benefits and risks of any procedure can be challenging, the challenges may be magnified with new procedures or technologies. Nevertheless, conducting these discussions well is an area of great scientific, ethical and public interest. Surgeons must be as forthright and balanced in the presentation of information as possible $[1,7,11]$.

Considering the topic of "informed consent", a word about semantics may be useful. It has been customary to refer to the process of discussing treatment risks, benefits and alternatives with patients as "getting consent". Using these terms devalues this critical interaction and is misleading regarding the dynamic. The discussion between the neurosurgeon and patient (and family) is a process of listening, understanding, educating, building trust and advising. Patients should not permit doctors to do things to them. They should request doctors to do things for them after the they have been well informed and empowered to make decisions that fit their beliefs, values and choices.

You may wonder why I ended up in such a philosophical excursion. But the fundament upon which all our knowledge and learning rests is the inexplicable. Reading this case report reminded me of my thoughts on how to do something as unusual as starting neuroendoscopy in the first place. And I realised that I had become more reluctant to change, to dare to take another step ahead. In the case presented here, I am sure I would have chosen the 'more obvious' approach and not the much longer and more dangerous route that the authors did. But is this different from performing an ETV for the first time while the 'obvious' treatment is just placing a shunt? Certainly not, and the authors have described their thinking process to do the best for their patient, the therapeutic imperative that is always present. They succeeded and should be commended for their skills that provided a good result for their patient.

\section{References}

1. Emanuel EJ, Wendler D, Grady C (2000) What makes clinical research ethical. JAMA 283:2701-2711

2. Felleti A, Alicandri-Cinfelli M, Pavesi G (2016) Transaqueductal trans-Magendie fenestration of arachnoid cyst in the posterior fossa. Acta Neurochir

3. Freedman B (1987) Equipoise and the ethics of clinical research. N Engl J Med 317:141-145 
4. Graham, Daniel W (2015) The stanford encyclopedia of philosophy. In: Zalta EN (ed), Fall 2015 edn. http://plato.stanford.edu/ archives/fall2015/entries/heraclitus/. Accessed 27 Jan 2016

5. Jouanna J (1988) Hippocrate: oeuvres complètes. Collection Budé. 5 (part 1)

6. Maclean I (2002) Logic, signs and nature in renaissance. The case of learned medicine. Cambridge University Press

7. McKneally MF (1999) Ethical problems in surgery: innovation leading to unforeseen complications. World J Surg 23:786-788

8. NIH. The Belmont Report (1979) Ethical principles and guidelines for the protection of human subjects of research. http://www.hhs.gov/ ohrp/humansubjects/guidance/belmont.html. Accessed 25 Jan 2016

9. Sachdeva A, Russell T (2007) Safe Introduction of new procedures and emerging technologies in surgery: education, credentialing, and privileging. Surg Clin N Am 853-866
10. Solomon MJ, McLeod RS (1995) Should we be performing more randomized controlled trials evaluating surgical operations. Surgery 118:459-467

11. Strong VE, Forde KA, MacFadyen BV, Mellinger JD, Crookes PF, Sillin LF, Shadduck PP (2014) Ethical considerations regarding the implementation of new technologies and techniques in surgery. Surg Endosc 28(8):2272-2276

12. Weijer C, Shapiro SH, Glass KC (2000) For and against: clinical equipoise and not the uncertainty principle is the moral underpinning of the randomised controlled trial. BMJ 321:756-758

13. Wicks R (2015) "Arthur Schopenhauer", The stanford encyclopedia of philosophy. In: Zalta EN (ed), 2015 edn. http:// plato.stanford.edu/archives/spr2015/entries/schopenhauer/. Accessed 24 Jan 2016 